\title{
PROGRAM OF PALLIATIVE CANCER CARE - OUR EXPERIENCE
}

\author{
Iva Slánská, Jindřich Kopecký, Stanislav Filip
}

Charles University in Prague, Faculty of Medicine and University Hospital in Hradec Králové, Czech Republic: Department of Clinical Oncology and Radiotherapy

Summary: Introduction: Annually more than 27,000 persons die of cancer in the Czech Republic and the overall incidence of malignancies is still increasing. These data shows the need for affordable and good follow-up care especially for patients without any cancer treatment due to irreversible progression of tumor. Currently the outpatient palliative cancer care gets more into the forefront. Prerequisite for a well working outpatient palliative care is cooperation with general practitioners and home health care agencies. The purpose of the so called program of palliative cancer care is to guide a patient in palliative cancer care and to improve the cooperation among health care providers. Methods: During the period from January 2008 to October 2010 we evaluated in patient without any oncology treatment due to irreversible progression of tumor. Results: In palliative outpatient clinic we treated 446 patients, 119 of them received home care services with average length of 27.8 days. 77 patients died at home, 51 in health facilities and 41 in inpatient hospice care. Conclusion: We present pilot study focusing on outpatient palliative cancer care which shows the real benefit from early indication of palliative cancer care. This type of care allows patients to stay as long as possible at home among their close relatives

Key words: Palliative cancer care; Onkology; Outpatient clinic

\section{Introduction}

The Czech Republic is ranked among those countries with the highest cancer burden in Europe and worldwide. Each year more than 27,000 persons die of cancer (1). These data clearly demonstrate the need for affordable and good follow-up cancer care for patients including also palliative cancer care.

Definition of palliative care is very difficult and it is necessary to understand palliative care as philosophical and methodological approach to patient. World Health Organisation defines palliative care as approach that improves the quality of life of patients and their families facing the problem associated with life-threatening illness, through the prevention and relief of suffering (2).

Palliative cancer care is an active medical and nursing intervention and its success depends on its timeliness, availability and organization of health care. The interdisciplinary team led by oncologist is a prerequisite for successful and good palliative cancer care to ensure continuity of health care through the end of life period. This presupposes that oncologist should have knowledges in palliative medicine or he should cooperate with professional specialist in palliative medicine. The main aim of palliative cancer care is to ensure the best possible level of quality of life for cancer patients and their family members. Palliative cancer care respects the individuality of the person in accordance with the basic conceptual model of quality of life, which consists of four basic dimensions - medical, psychological, spiritual and social aspects.
In advanced stages of cancer, it is important to be aware of objective risk factors (e.g., progressive cancer anorexia, type and stage of cancer, irreversible changes in organ function, etc.), that may significantly affect the palliative cancer care $(3,4)$. However, these risk factors may individually vary in response where and how the palliative cancer care itself is provided (inpatient or outpatient care). The proper evaluation of these risk factors is not only important for further determination of strategy about the management of the patient in palliative cancer care, but it also conceals the economic and ethical impacts (5).

When determining the plan of palliative cancer care, any physician providing this kind of care should be able to answer the following questions: when, where and what kind of form the palliative cancer care will take?

The first question is about the proper timing of initiation of palliative cancer care. In a time of great medical advance it is very difficult to decide about termination of cancer treatment and that's why such decision should be done by a team composed of professionals (doctors and nurses) in cooperation with the patient and his family (6). The second question deals with the availability of palliative cancer care in the health care system. The third question focuses on the implementation of palliative cancer care into cancer treatment itself (6).

In Hradec Kralové region the program of palliative cancer care was created, which is supposed to unify the attitude in providing this care with regard to the above mentioned three questions. In this article we present the first results from the provision of outpatient palliative cancer care. 
These results underscore the current trend of shift to the outpatient palliative cancer care, despite of some health and social difficulties.

\section{Methods}

\section{Patient and inclusion criteria for palliative cancer care}

We evaluated information from patients, who were visiting our outpatient palliative clinic from January 2008 to October 2010. All patients were without any cancer treatment. See patient characteristics in Tab. 1 and Tab. 2. For validation of performance status we used the ECOG scorinng system (PS $0=$ Asymptomatic, Fully active, able to carry on all predisease activities without restriction; PS 1 = Symptomatic but completely ambulatory, Restricted in physically strenuous activity but ambulatory and able to carry out work of a light or sedentary nature. For example, light housework, office work; PS $2=$ Symptomatic, $<50 \%$ in bed during the day, Ambulatory and capable of all self care but unable to carry out any work activities. Up and about more than $50 \%$ of waking hours; PS $3=$ Symptomatic, $>50 \%$ in bed, but not bedbound, Capable of only limited self-care, confined to bed or chair $50 \%$ or more of waking hours; PS 4 = Bedbound, Completely disabled. Cannot carry on any self-care. Totally confined to bed or chair; PS 5 = Death).
Tab. 1: Characteristics of patients

\begin{tabular}{|l|c|c|c|}
\hline & & Avarage age & Range of age \\
\hline Men & 158 & 56 & $18-96$ \\
\hline Women & 288 & 61 & $20-81$ \\
\hline Total number & 446 & & \\
\hline
\end{tabular}

\section{Outpatient palliative clinic}

Outpatient palliative cancer care is part of Cancer centre that has in its register more than 500,000 inhabitants. Outpatient palliative clinic has begun on 1 January 2008. The health and social interventions are provided by a professional team, which consists of a clinical oncologist algesiologist, specialists in palliative medicine, social consultant, nutritional therapist, psychotherapist, pastoral assistant and nurses educated in palliative cancer care issue. Outpatient palliative clinic has 5 beds in day care centre, which are used to perform miniinvasive procedures such as relieving chest and abdominal puncture or to application of supportive infusion therapy.

\section{Monitored parameters}

Monitored parameters were: age, performance status, sex, primary oncological diseases, total follow-up period

Tab. 2: Characteristics of patients

\begin{tabular}{|c|c|c|c|c|c|c|}
\hline & & \multicolumn{5}{|c|}{ Performance status at the beginig of palliative cancer care } \\
\hline Diagnosis & Number of Patients & PS 0 & PS 1 & PS 2 & PS 3 & PS 4 \\
\hline Colorectal cancer & 95 & 20 & 43 & 20 & 11 & 0 \\
\hline Anal cancer & 66 & 21 & 21 & 19 & 8 & 0 \\
\hline Breast cancer & 64 & 30 & 25 & 8 & 1 & 0 \\
\hline Pancreatic cancer & 36 & 11 & 16 & 5 & 2 & 0 \\
\hline Ovary cancer & 31 & 19 & 10 & 1 & 1 & 0 \\
\hline Head and Neck cancer & 26 & 7 & 11 & 5 & 3 & 0 \\
\hline Lung cancer & 24 & 6 & 16 & 1 & 1 & 0 \\
\hline Stomach cancer & 17 & 9 & 5 & 2 & 1 & 0 \\
\hline Kidney cancer & 16 & 10 & 3 & 2 & 1 & 0 \\
\hline Endometrial cancer & 14 & 11 & 2 & 1 & 0 & 0 \\
\hline Prostate cancer & 14 & 8 & 3 & 3 & 0 & 0 \\
\hline Esophagus cancer & 13 & 10 & 1 & 1 & 1 & 0 \\
\hline Bladder cancer & 11 & 6 & 3 & 1 & 1 & 0 \\
\hline Bilary tract cancer & 7 & 1 & 1 & 3 & 2 & 0 \\
\hline Hepatocellular cancer & 5 & 2 & 0 & 3 & 0 & 0 \\
\hline Melanoma & 5 & 1 & 3 & 1 & 0 & 0 \\
\hline Thyroid cancer & 2 & 1 & 1 & 0 & 0 & 0 \\
\hline
\end{tabular}


in our outpatient palliative clinic, average number of indicated and provided services by home care services, number and location of patients who died.

\section{Results}

\section{An evaluation of outpatient palliative cancer care}

The average number of outpatient visits with clinical examination by clinical oncologist was $2.4 \times$ per month. The average number of consults provided by outpatient palliative clinic for other outpatient clinics or hospital departments was $23.7 \times$ per month. The average number of consultations requested by the home care services or patient's family was $7.4 \times$ per month. The average number of consultations requested by the general practitioners was $1.2 \times$ per month.

\section{Total number of patients who died}

In the reporting period 169 patients died, 95 women with average age of 69 years (range 20-81 years) and 74 men with average age 59 years (range 18-96 years). 77 $(45.6 \%)$ patients died at home, $51(30.2 \%)$ in hospital and $41(24.3 \%)$ in inpatient hospice.

\section{An evaluation of home care services}

The number of patients, to whom the home care was provided, was $119(26.7 \%)$. The average number of home visits made by general practitioners was $0.7 \times$ per month. The average number of visits of home care nurses was $9.6 \times$ per month. To 47 (39.5\%) patients the full home care service (nursing screening, rehabilitation, nutritional counselling, nursing care and administration of supportive infusion) was provided. The average length of home care was 27.8 days (range $12-61$ days).

\section{Discussion}

Palliative cancer care is a serious problem in health care system (7). Therefore the basic concept of palliative cancer care was created by Czech society for oncology and Czech society of Palliative medicine. Based on this concept we established in our region a program of palliative cancer care. The main reason for creating this program was the belief that the implementation of palliative cancer care into daily oncology practice may improve the quality of life for cancer patients. Palliative cancer care is provided at different levels of health care. The crucial role plays the good and coordinated cooperation of clinical oncologist with general practitioners, regional oncology outpatient clinics, home care agencies and inpatient hospice. Based on our experiences the outpatient palliative cancer care has invaluable role in the time when there is no other possible cancer treatment until to the terminal stage of disease. The care is not focused only on somatic problems, but also social and psychological ones. Providing of this type of care requires professional erudition in the palliative medicine in order to detect situations when the patient does necessarily require a change of palliative approach or intensification of the palliative cancer care (8).

From our experience the regular monitoring of health status in form of outpatient's visit is very important so that the cooperation with patient and his family could be optimal.

Home care agencies and facilities providing palliative care play an essential role in palliative cancer care. It is always necessary to identify, depending on the patient's specific needs and wishes, the appropriate agency or facility as far as possible so that the patient's quality of life could be reached (9).

Our results and experiences point out the fact that it is possible to achieve the main goals of palliative medicine in the form of outpatient care.

\section{Conclusion}

Our results underscore the current trend in palliative cancer care where the outpatient care is preferred. The biggest problem in providing of palliative cancer care is the proper indication or adequate changing program of palliative cancer care. In addition the introduction of a uniform terminology and style in keeping of medical records help us to find a common language with home care services. However, our experience has shown that the continuous education in the field of palliative medicine is still needed - and especially of general practitioners who are one of the most important components in the palliative cancer care.

\section{Acknowledgements}

This study is supported by grant MZO 00179906 of the Czech Republic and grant SVV No. 40050 Charles University in Prague of the Czech Republic.

\section{References}

1. Dušek L, Mužík J, Gelnarová E, Fínek J, Vyzula R, Abrahámová J. Cancer Incidence and Mortality in the Czech Republic. Klin Onkol 2010; 23: 311-24.

2. World Health Organization. Definition of Palliative Care. World Health Organization Web site. (Accessed December 4, 2011, at http://www.who.int/cancer /palliative/definition/en/)

3. Maltoni M, Garacen A, Brunelli C, et al.: Prognostic factors in advances cancer patients: Evidence-based clinical recomendation - a study by the steering committee of the European Association for Palliative Care. J Clin Oncol 2005; 23: $6240-48$.

4. Hui D, Arthur J, Dalal S, Bruera E. Quality of the supportive and palliative oncology literature: a focused analysis on randomized controled trials. Support Care Cancer. 2011 Sep 21. [Epub ahead of print]

5. Filip S, Svoboda V, Zouhar M, et al. The evaluation of medical and economic indices of palliative care in oncologic patients. Klin Onkol 2007; 2: 209-14.

6. Filip S, Slováček L, Švecová D, et al. Outpatient clinic of palliative care in oncology. Časopis Lék Čes 2011; 3: 169-72.

7. Sláma O, Špinka Š. Koncepce paliativní péče v ČR. Pracovní materiál k odborné a veřejné diskusi. (Accessed January 12, 2012 at http://www.cestadomu.cz/res /data/028/003426.pdf) 
8. Slováček L, Priester P, Kopecký J, et al. Palliative cancer care within the Hradec Králové region health care system: own experience. Klin Onkol 2011; 24 $265-70$.
9. Slováček L, Šimková M, Petera J, Filip S. Can cancer patient in terminal stage of cancer die with dignity at home? And under what conditions?. Klin Onkol 2011; 24: 221-23.

Received: 23/03/2012

Accepted in revised form: 10/01/2013

\section{Corresponding author:}

Iva Slánská, M.D., Department of Clinical Oncology and Radiotherapy, University Hospital in Hradec Králová, Sokolská 581 50005 Hradec Králové, Czech Republic; e-mail: slansiva@fnhk.cz 